\title{
Content and Language Integrated Learning for First and Second Year University Students - Aspirations, Challenges and Solutions
}

\author{
Mark Brooke \\ Centre for English Language Communication, National University of Singapore, Singapore
}

\begin{abstract}
This paper offers an overview of two modules from the Centre for English Language Communication, National University of Singapore. These belong to a programme entitled the Ideas and Exposition Modules (IEM) and they pertain to a content and language integrated learning (CLIL) approach. The courses and some of the main learning objectives are explained. These are critical thinking abilities; research skills; and academic study skills. It is surmised that these are useful for all students independent of their academic discipline. The challenges that the lecturer and students face during the courses are also presented. These challenges often arise because students are from different educational cultures and academic disciplines, and as a result, classes tend to be comprised of students with mixed interests, English language levels and academic research and writing experience. Students also tend to vary in their abilities to think critically and work independently. The first section in this paper looks at the educational context of the IEM courses; the second, presents the core learning outcomes aspired to; the third, examines the challenges faced and how these are met by the tutor and students taking the courses. The final section offers a brief overview of the paper and considers the future for this genre of course, particularly how students benefit from a more student-centered, individualized educational practice today.
\end{abstract}

Index Terms - tertiary education, content and language integrated learning, critical thinking dispositions, academic research skills, academic writing skills, academic English language

\section{CONTEXT}

The courses pertain to a pedagogy known as content and language integrated learning. This approach to language instruction centres on using a specific academic field as a medium through which to teach specific but also general cross-curricular academic language as well as critical thinking and research skills. Zwier's (2008, p. 21) overlapping variations of language development can be used to explain the processes of language learning in society. During the first years, a person learns their basic language, or basilect. From then on, people learn more formal, academic language and become increasingly specialized in a particular content field or discipline as they go on to further education or the workplace. Dutro and Moran (2003) have constructed a commonly applied metaphor to describe this: the bricks and mortar metaphor; whereby general cross-curricular academic language is the mortar and content-specific language from subject areas, the bricks. As a paradigm, CLIL strives to enable students to learn both the bricks and mortar thus providing students with a language-acquisition-rich environment; and because of this, one that is cognitively challenging (Baetens-Beardsmore, 2008; Marsh \& Fregols, 2013).

The context for the courses is Singapore. Most Singaporeans entering tertiary programmes have a good grasp of English as an academic language. They are very capable of functioning in an English medium academic classroom environment. However, in the college programmes that IEM caters to, it is also common to have scholars from Korea, Japan, Vietnam, and mainland China. In addition, many Singaporeans come from homes where Mandarin, Malay or Tamil are spoken as their first languages. For them, English is an additional language. In this context, it is thus used as a lingua franca, which links these courses within the broad educational field of CLIL. The CLIL academic writing courses are delivered by content specialist related to the sociology of sport. The courses run over twelve weeks and comprise around forty-eight contact hours. Several individual consultation sessions are woven into this timeframe. One major element of teaching these classes is the small student population; the maximum number of students to a class is fifteen, allowing a great deal of teacher-student and student-student interaction, including one-to-one consultations and peer assessment sessions.

For both IEM modules, students are required to write three texts. For first years (IEM1), these are a summaryreflection, a paper comparison or lens paper, and a final argumentative persuasive essay (APE) of 1500 words. For second years (IEM2), they are an annotated bibliography, a research proposal and a research paper, or IMRaD (Introduction-Methodology-Results-Discussion), of approximately 3000 words. In each case, learning is facilitated as a construction process. The summary-reflection leads onto the paper comparison/ lens paper task, which might be two summaries plus a reflection to compare these or it might be a summary plus the application of a lens as a theoretical framework through which to analyze the phenomenon summarized. Both of these papers enable students to learn how to 
use sources and to cite them as a part of their argumentation. These tasks culminate in the APE as the third paper, which builds on the knowledge and critical thinking acquired to develop an evidence-based study. For IEM 2 the construction process leads to the IMRaD research paper proper. The first task, the annotated bibliography, is the basic reading the students have done on their chosen topics. This task provides both the tutor and students with an overview of the phenomenon and the issues and opinions around it. The second task, the research proposal conveys to the teacher that students have progressed from the initial background reading to pinpoint an appropriate investigation that will produce new knowledge in that field. This paper states what the objectives of the research are and how they will be achieved. Paper 3, the final research paper, presents the results, discussion and conclusion emerging from the investigation. Again, it is essential that students demonstrate the knowledge and critical thinking necessary to develop an evidence-based study.

In the next section, there is a presentation of the main learning outcomes to which the courses aspire.

\section{CONTENT}

During his opening speech in 1997 at the 7th International Conference on Thinking, Goh Chok Tong, the then Singaporean prime minister, revealed:

Education and training are central to how nations will fare in the future. Strong nations and strong communities will distinguish themselves from the rest by how well their people learn and adapt to change. The task of education must therefore be to provide the young with the core knowledge and core skills, and the habits of learning, that enable them to learn continuously throughout their lives. We have to equip them for a future that we cannot really predict.

Facilitating lifelong learning forms the core of Singapore's educational practices whatever the university discipline or field of employment. However, what do lecturers choose to teach their students to provide them with this core knowledge and these core skills, and habits of learning? Once these have been identified, how is this done? This section aims to answer these questions.

\section{A. Critical Thinking Skills}

As Teine (2000) argues, teaching is not merely transmission, nor is acquisition a simple process of storing and retrieving knowledge. If knowledge is to be acquired, there needs to be conscious activity that evaluates and organizes information; there also needs to be a communicative situation in which that information can be used, and elaborated on, in context. When educators discuss cognitive engagement of this sort, they often employ Bloom et al.,'s (1956) taxonomy or perhaps Anderson et al.,'s (2001) revised version of that to construct instructional activities to facilitate learning. For example, a student might be asked to classify items (taxon 4). However, for these courses, which focus particularly on the writing of academic expository genres at the tertiary level, the taxonomy from Ennis (1994) entitled Critical Thinking Dispositions (see Harvard's Graduate School of Education website) has been found to be more appropriate. It really starts at the highest of Bloom's levels e.g., to evaluate an opinion (taxon 6).

Ennis (1994) states that 'critical thinking is reasonable and reflective thinking focused on deciding what to believe or do' (p. 1). He (1994) continues:

In brief, the ideal critical thinker is disposed to try to "get it right," to present a position honestly and clearly, and to care about others (this last being auxiliary, not constitutive); furthermore the ideal critical thinker has the ability to clarify, to seek and judge well the basis for a view, to infer wisely from the basis, to imaginatively suppose and integrate, and to do these things with dispatch, sensitivity, and rhetorical skill (p. 5).

Ennis (1994) posits that in order to make a sound decision, it is necessary to employ a set of thinking dispositions. He defines thinking dispositions as types of high level reflection under specific conditions. He advances fourteen of these high-level thinking dispositions. For the IEM courses, they have been integrated into five overarching descriptors. They move from the input to output stages or from critical reading to independent critical writing about a phenomenon based on an investigative process.

The first descriptor is for students to consider with care and kindness what other authors say and to ensure that they understand correctly what these authors are communicating; this descriptor might be used to assess a synthesis of a source for IEM1, or as part of a literature review in IEM2. Also, in relation to this descriptor, if another's position seems less limited than their own, students should be able to change their minds and take on this alternative view. This may emerge in IEM1 as part of a reflection on a summary, or in a discussion section for IEM2. The second descriptor is to provide evidence of critical evaluation of an author's position through argumentation by assessing the claims and evidence provided. Again, these may surface as part of a reflection or discussion section for the relevant IEM module. The third, fourth and fifth descriptors from the IEM modules relate to Ennis' dispositions on selecting and using sources and evidence in students' own writing based on their own investigations. Students must strive to demonstrate that they are using credible primary and secondary sources; they should provide sound argumentation by positioning their own investigations within the broader academic field. They should also draw warranted conclusions from their investigations and demonstrate an ability to defend their informed position. The teacher and students focus explicitly on these descriptors use them to guide the input and output stages of the courses. They form a substantial part of the core knowledge.

\section{B. Autonomous Learning}


A rich learning environment is one whereby:

Prime emphasis is placed on the unique interests, styles, motivations and capabilities of individual learners so that learning environments can be tailored to them (Reeves, 1992, p.1).

The view of students as recipients of knowledge has shifted to beings that are intrinsically motivated and autonomous. According to Self-Determinism Theory (Deci \& Ryan, 1991, p. 327), autonomy refers to being self-initiating and selfregulating of one's own actions. This view is closer to a being's natural state, one which is active and volitional, innately primed to learn, and to evolve. It is important to help students in tertiary education to learn how to manage their own learning, and to provide them with as many opportunities to learn knowledge and skills relevant to their particular intrinsic interests within a domain.

Such learning management skills are outlined and assessed in the University of Adelaide Research Skill Development Framework as the ability to collect and record self-determined information from self-selected sources; organize information using self-determined structures; and to analyze and create information to fill self-identified gaps. The courses seek to construct a teaching and learning environment in which this framework can be applied. Once enrolled, students are exposed to primary (photos; video footage; films; geographical documents; speeches) and secondary sources (typically readings from academic journal papers related to the module). They are then encouraged to choose a topic related to this content to develop as a line of inquiry. For IEM1, the product that students construct is a 1500-word APE; for IEM2, it is an IMRaD of 3000 words. As classes are limited to fifteen students, the tutor and the student can work together as participants in a process of constructing these papers. The tutor guides the processes of choosing appropriate theoretical frameworks, research methodology or data from multiple sources, to facilitate argumentation but it is the student who is encouraged to regulate the process throughout.

\section{Giving Voice to Learning and Facilitating Collaborative Elaboration}

Knowledge is not only independently constructed but also socially and culturally constructed (Prawat \& Floden, 1994). The process of sharing individual perspectives and mutually-negotiating meanings to construct shared knowledge is known as collaborative elaboration (Van Meter \& Stevens, 2000). This is said to lead to understanding which goes beyond the understanding that an individual alone can construct (Ritchhart, Church, \& Morrison, 2011). Groups are also known to remember information for longer periods than individual students (Johnson et al., 1990) because this is deemed 'an ongoing, collective responsibility' (Opfer \& Pedder, 2011, p. 385). The result of this mutualconstruction is termed distributed cognition (Vrasidas et al., 2003b). In addition, the value of another person's perspective, usually gained through interaction, is a key philosophy in social constructivist theories (Cochran-Smith \& Lytle, 1993; Jonassen, 1994). Being able to respect each individual's opinion and work is an essential pre-requisite to collaborative elaboration. Students entertain each other's views and often collaboratively analyze which one may be more appropriate.

A key approach of the IEM1 and IEM2 courses is to respect and empower each student by encouraging them to give voice to their learning. For IEM1, students are asked to present their research papers to the class at the end of the semester. They may be provided with a framework with which to do this. For IEM2, students are required to present the core readings of the syllabus during the semester; they are also required to present their own research at the end. All presentations are followed by a question and answer session. Students are encouraged to use multiple modes for these presentations. Very often, video extracts are used particularly if using a popular culture topic such as a film for a primary source. Commonly, the tutor will do one or two paper presentations first at the beginning of the module to model how this can be done. A comfortable, enthusiastic and scholarly classroom environment is sought to make these presentations and the post-presentation Q\&A sessions worthwhile learning experiences.

In addition to presentations, group work and the sharing of learning make up an essential aspect of each module. This materializes in several forms throughout the semester. In most sessions, students are asked to do related tasks in groups after these presentations. They might be asked to research a topic further and a debate might be instigated from these findings. They could be required to identify and analyze the weakness of a paper's methodology to discuss its reliability. The general goal is that the tasks develop conversation and culminate in an open class or roundtable discussion using the paper presented as a platform or springboard. An additional avenue for collaborative learning is through conducting guided peer evaluation. Class time is given throughout the writing process for students to receive and offer advice on their writing from their classmates. They may be provided with a framework for this also. Again, one of the important messages from this experience is that valuing other viewpoints is essential in an effective classroom.

In the next section, the challenges faced by the tutor and students and how they are met are presented.

\section{Challenges AND Solutions}

\section{A. Guiding Students to Conduct Research Independently}

In IEM1, as first years, students tend to be writing independently-chosen research papers, using multiple sources, for the first time. Even writing a 1500-word paper is a daunting task for any inexperienced researcher embarking on a topic related to an entirely new content field. For IEM2, even though students have developed skills in research, the task is more challenging as they are required to write a 3000-word IMRaD. Difficulties for both IEM modules often arise at the 
beginning stages of the students' projects. Students often face challenges finding a topic to write about; and having the right scope for a paper. This can also cause challenges for the tutor as students might not be able to meet deadlines for consultations, presentations or submission of papers. For example, a student on a Sociology of Sport paper might wish to examine hegemonic masculinity in sport. This investigation would need framing by choosing a particular sport to study and a context in which to study it. It could even report on an event that inspired the topic selected to study. For example, the US women's soccer team's victory in the 1999 World Cup was swamped in controversy when Brandi Chastain scored the winning goal in a penalty shoot-out against China and famously dropped to her knees, took her shirt off and celebrated in her sports bra. This image was on the main cover of Sports Illustrated and the front pages of newspapers around the world and seemed to be of greater significance than the victory itself. If this is chosen, the next step is to apply the theoretical framework as a lens: why are women scrutinised in this way by the media? What kind of disciplining gaze are they subjected to? If students are doing an IEM2 module, would they also prefer to conduct interviews to ascertain whether people today still think that Chastain's action was wrong even though this sort of behaviour is commonly condoned among men?

In order to facilitate the research and writing of such a project, the tutor can provide the sort of guidance demonstrated above; a tutor can also help students to meet the challenges by offering advice on study skills. Strategies such as how to brainstorm and organise their ideas using mind or concept mapping or tree diagrams; how to find, select, evaluate and acknowledge sources; how to annotate a text; how to quote and paraphrase; how to prepare and present evidence; and how to write reference sections. In IEM2, for which students are required to write a much larger piece, these same skills might be taught, but other, more appropriate ones might also be covered. For example, one effective method for source grouping is a synthesis grid, also known as a synthesis matrix, enabling learners to store information and evidence in tabular form. Once relationships between sources have been identified, learners can take notes in the squares of the grid. On the $\mathrm{Y}$ axis of the grid, the learner usually provides the details of the source; on the $\mathrm{X}$ axis, the links between the sources are used as themes. A simplified example of a synthesis grid is provided below in figure 2 . It is from an IEM2 student writing a paper on how athletes tend to justify certain behaviours in sport e.g., taking drugs to boost performance or diving in football.

TABLE 1.

EXAMPLE SYNTHESIS GRID FROM AN IEM2 STUDENT

\begin{tabular}{|c|c|c|c|c|}
\hline Source & $\begin{array}{l}\text { Moral } \\
\text { disengagement } \\
\text { techniques }\end{array}$ & $\begin{array}{l}\text { Competitive or non- } \\
\text { competitive sports } \\
\text { environment }\end{array}$ & Characteristics of technique & $\begin{array}{l}\text { Results of technique } \\
\text { as related by } \\
\text { psychologists. }\end{array}$ \\
\hline $\begin{array}{l}\text { Boardley, I. J. \& Grix, J. (2014). } \\
\text { Doping in bodybuilders: A } \\
\text { Qualitative Investigation of } \\
\text { Facilitative Psychosocial } \\
\text { Processes. Qualitative Research } \\
\text { in Sport, Exercise and Health, } \\
\text { 6(3), 422-439. }\end{array}$ & $\begin{array}{l}\text { Bandura's social } \\
\text { cognitive theory }\end{array}$ & Non-competitive & $\begin{array}{l}\text { - Moral justification } \\
\text { - Euphemistic labelling } \\
\text { - Advantageous comparison } \\
\text { - Displacement of } \\
\text { responsibility } \\
\text { - Diffusion of responsibility }\end{array}$ & $\begin{array}{l}\text { Euphemisms are } \\
\text { effectively used } \\
\text { daily to sanitize/ } \\
\text { disguise e.g., drugs } \\
\text { referred to as juice. }\end{array}$ \\
\hline $\begin{array}{l}\text { Corrion, K., Long T., Smith, A. } \\
\text { L., Arripe-Longueville, F. (2009). } \\
\text { "It's Not My Fault; It's Not } \\
\text { Serious": Athlete Accounts of } \\
\text { Moral Disengagement in } \\
\text { Competitive Sport. The Sport } \\
\text { Psychologist, 23, 388-404. }\end{array}$ & $\begin{array}{l}\text { Bandura's social } \\
\text { cognitive theory }\end{array}$ & Competitive & Ibid & $\begin{array}{l}\text { Diffusion of } \\
\text { responsibility - } \\
\text { frequency of } \\
\text { acts e.g., fouling in } \\
\text { sport, weakens } \\
\text { morality associated } \\
\text { to it. }\end{array}$ \\
\hline $\begin{array}{l}\text { Sefiha, O. (2012). Bike Racing, } \\
\text { Neutralization, and the Social } \\
\text { Construction of Performance- } \\
\text { Enhancing Drug Use. } \\
\text { Contemporary Drug Problems, } \\
\text { 39, 213-245. }\end{array}$ & $\begin{array}{l}\text { Neutralization } \\
\text { technique }\end{array}$ & Competitive & & \\
\hline
\end{tabular}

As students make progress through their research projects, they are increasingly expected to identify relevant primary and secondary sources. Whatever the content-specific focus of the project, this type of strategy is very useful in guiding students to read and organize their readings.

\section{B. Learning with Students}

Even if the tutor is a content specialist, it is not common not to be fully familiar with the field of inquiry that all of the students are following. For example, in a Sociology of Sport module, during one semester, it is common for there to be forty-eight considerably different topics. Some examples are: prosthetic technology for amputee athletes; the exploitation of child gymnasts in mainland China; the role of the Foreign Talent Sporting Scheme in Singapore; the ethical dilemmas of fetal doping; Wu Shu and masculine hegemony; the Olympics and the status of transgendered athletes. The differing theoretical frameworks that are used as lenses for these studies are as diverse as the topics themselves. For example, it is common for students to apply critical approaches through Gramsci, Bourdieu, Foucault and Althusser or Functionalist theory via Durkheim and Parsons or Symbolic interactionism via Mead and Cooley. 
Due to this diversity, the challenges the tutor faces working on this genre of module can really only be met as coinvestigators, working to research the students' topics as an ongoing project. In this way, the tutor is not solely a transmitter of information but a 'guide on the side' in the real sense of the term, working to help the students manage their projects. As co-investigator, it is common to share tasks with students, to find appropriate sources for a student's project or to co-code a student's qualitative data and provide investigator triangulation to enhance reliability. If the tutor demonstrates enthusiasm for the project, this co-investigation can create a strong relationship between the student and tutor. It is common, during a tutorial, to hear the tutor using we (first-person, plural personal nominative pronoun) during a discussion. For example, yes, that's what we should do now... or no, you're right, we don't want to argue that.

In most educational settings, this may be unheard of, and it might seem unthinkable to educational traditionalists. It is a very student-centric mode of learning as it is the students who autonomously regulate their projects, disciplining themselves to conduct the appropriate reading or empirical research required for their work to progress satisfactorily. However, it is exactly this ownership of their own learning that ensures the quality of the students' work. Because of this, the students need to prepare well for the consultations as they are taking a lead role in them. They commonly show the tutor what they have found and written, ask for feedback on this and manage the next phase in their projects by agreeing with their tutor about what is to be done and how it should be done. The overall result is a very positive one. Over the course of the two years, from IEM1 as a first-year student to IEM2 as a second-year student, there is a clear difference in the ways that students perceive their studies. They develop much more independence and responsibility for their own learning and are more capable of making decisions about the content and research or writing processes. Another consequence of the development of independence can be seen during the peer evaluation sessions. IEM2 students see much more value in these sessions as they recognize that their peers are informed practitioners and thus, confident critical readers.

\section{Consulting Students on Language and Genre}

It has been noted that the IEM classes typically consist of students with marked differences in knowledge of English language and how to write academic English texts. The tutor therefore needs to be able to teach language (a lexicogrammatical focus) and how texts are constructed (a discourse focus). There is typically a requirement for a focus on lexico-grammatical areas, particularly systematic errors committed by students; common errors are related to endorsing authors and distancing from authors; using modality; passive constructions; and concessive clauses. One consistent idiosyncratic error is distinguishing between singular or plural nouns and conjugating them with the correct inflection of the verb. Despite these similarities, there is often too much diversity for a tutor to feedback at the class level, even if the class size is small. The feedback in these areas is therefore often given through individual consultations.

One effective way to offer feedback is through Socratic Dialogue, embedding probing statements or questions, or highlighting words, phrases or sections that require attention on the students' papers. An example problem sentence is offered below:

Lastly, there have not been many researches regarding gender stereotypes in softball, and no research has been done about this topic in Singapore's context.

There are two uses of research here, one as a count noun another as a noncount noun. Clearly, the second use is more appropriate and to make this evident to the student, the tutor might provide the following activity:

One of the uses of research is correct. Which one? What happens to the verb if the noun is noncount? If you are not sure, please use a grammar reference and then visit https://owl.english.purdue.edu/owl/resource/541/01/ and read about it.

In this way, the tutor is engaging the students in two-way asynchronous communication, interacting with them and guiding them to notice what is problematic in their texts. The student is required to provide an answer in her work. The tutor has several methods for providing feedback in this way: using assessment systems built into virtual learning environments; simply using the review function in Microsoft Word; or utilizing software such as In2go, an annotation and screen recording tool that allows writing on top of an active desktop application such as Word in real time and recording a live video of the feedback for the student. Whatever the method used for the feedback, this practice is deeply grounded in discovery learning. Students are provided with the means to study the grammar; thus, shifting the responsibility over to them. Again, this is clearly an example of the tutor as 'guide on the side', which is very much consistent with learner-centered methodology (Blumberg, 2009). Nunan (1988) argues that using the students' own writing to teach language on a needs-based format is a far more superior approach to pre-course language syllabus design. It is a bottom-up, not a top-down focus and one which encourages students to explore.

In addition, all students generally benefit from sessions on form and function at the discourse level, in particular, input on the characteristics of the given genres students are required to write. In IEM1, there might be a focus on how an introduction or body paragraph of an APE is constructed. In IEM2, there might be a focus on how to structure an original research paper with varying time spent on writing an introduction, literature review (a theoretical framework), methodology, results and discussion, and finally a conclusion. Although a tutor can work with students in consultations on these areas, it is also common to conduct this kind of instruction at the class level. One typical instruction session at discourse level is to teach IEM1 students how to write their APEs. This might involve deconstructing a paragraph by using themes relating to the controlling ideas of each sentence. Beyond the hyper-theme (topic sentence), sentences pertaining to the development section (body) have differing roles. Often, a sentence fulfils several or all roles 
simultaneously. These roles may be presented as the following: describing (providing extra information to supplement the controlling idea expressed in the hyper-theme); exemplifying (offering examples that help to illustrate the main idea); analysing (examining concepts related to the controlling idea); challenging (analysing information or views represented in sources concerning the controlling idea); persuading (constructing argumentation around the controlling idea); and. using supporting evidence (referencing sources which communicate or support the controlling idea). If students report that further work is required for this activity, they can be directed to a site such as Sydney University's eLearning Writesite devoted to persuasive academic writing to work independently until their competence, and confidence in this field has developed.

This may seem to follow a traditionalist approach. However, as already noted, critical thinking and collaborative elaboration are essential goals of the courses. By asking students to complete tasks such as the one described above in groups, these activities can help to develop knowledge and good habits of learning. Students generally find the sort of activity described above very challenging and enjoyable. The key is to choose the right level of academic language for the text being analysed. While groups are matching form and function, the instructor monitors and provides input when necessary. As a follow-up, groups may compare results and then go on to write their own paragraph on a topic related to the module during class time. This enables them to apply the instruction as it is processed and to take risks thereby learning from each other or from the tutor. Also, by connecting the students to an eLearning site such as that found at Sydney University's Writesite to further study this area, students are being guided to develop as autonomous learners, one of the essential habits of learning on the programme.

\section{CONCLUSION}

This paper has presented characteristics of two courses belonging to a particular academic writing programme at the Centre for English Language Communication of the National University of Singapore. The modules are content-specific. There is a deep-rooted connection to lifelong skills development; there is both learner and learning-centred approaches (Mostrom \& Blumberg, 2012); and technology is ubiquitous. A module of this type offers students multiple learning experiences. There are, of course, numerous challenges that emerge when striving to deliver these learning outcomes and these have been explained in this paper. Overall, the challenges centre on the difficulty of catering to diversity. In each classroom, it is possible to see significant differences in students' abilities to research and write in English. This is not only because of varying English language levels but also due to different academic experience: some students have been trained to write academic genres more than others; some are more autonomous learners than others; and some have more intensive majors to deal with during the semester making it hard for them to manage their study time. One clear conclusion from the growth of this genre of module is that, today in South-East Asia, there is a more humanistic and individually-sensitive educational paradigm that places great respect on each student and the space that they inhabit. Long gone are the behaviourist days when a student was a passive recipient, with a clean slate, a tabula rasa, waiting to be filled with whatever the teacher, or text book, considered important.

As educational practices move further into the twenty-first century, it is clear that this student-centric mode of learning will continue to grow. It is a paradigm that has evolved along with notions of life-long learning, which are inextricably linked to the opportunities that citizens have today. With the ubiquitous nature of technology, the tutor and students can find academic sources at the touch of a screen; they can consult excellent online resources devoted to training students how to write academic texts; they can also manage a great deal of their interactions asynchronously, and at a distance, using review or even screen casting software to provide in-depth, meaningful feedback to students' texts. The teaching and learning environment is truly inside and outside the classroom. In addition, due to the multitude of resources available and the speed with which they can be accessed, students have more opportunity to become informed and choose what they wish to study; this also offers them more independence, increasing intrinsic motivation and reducing the degree of teacher control. All of these observations point to the increasing role of the teacher as 'guide on the side', and the continued development of student-centric modes of learning. As long as class sizes can be kept low and students have the time to work on their projects, this can only have positive repercussions.

\section{REFERENCES}

[1] Adelaide University's Research Skill Development Framework http://www.adelaide.edu.au/rsd/framework/. Last accessed in June 2018.

[2] Anderson, L. W., Krathwohl, D. R., Airasian, P. W., Cruikshank, K. A., Mayer, R. E., Pintrich, P. R., \& Wittrock, M. C. (2001). A taxonomy for learning, teaching, and assessing: A revision of Bloom's taxonomy of educational objectives. White Plains, NY: Longman.

[3] Baetens-Beardsmore, H. (2008). Multilingualism, cognition and creativity. International CLIL Research Journal, 1(1), 4-19.

[4] Bloom, B. S. (Ed.). Engelhart, M. D., Furst, E. J., Hill, W. H., Krathwohl, D. R. (1956). Taxonomy of Educational Objectives. Handbook I: The Cognitive Domain. New York: David McKay Co Inc.

[5] Blumberg, P. (2009). Developing learner-centered teaching: A practical guide for faculty. San Francisco, CA: Jossey-Bass.

[6] Cochran-Smith, M., \& Lytle, S. (1993). Inside/outside: Teacher research and knowledge. New York: Teachers College Press.

[7] Deci, E. L., \& Ryan, R. M. (1991). A motivational approach to self: Integration in personality. In R. Dienstbier (Ed.), Nebraska symposium on motivation: Perspectives on motivation (pp. 237-288). Lincoln: University of Nebraska Press. 
[8] Dutro, S., \& C. Moran. (2003). Rethinking English language instruction: An architectural approach. In English learners: Reaching the highest level of English literacy (pp. 227-258). Newark: International Reading Association.

[9] Ennis, R. H. (2011). The Nature of Critical Thinking: An Outline of Critical Thinking Dispositions and Abilities. Proceedings from the Sixth International Conference on Thinking, MIT, Cambridge, MA, July 1994.

[10] Goh Chok Tong, (1997). Public speech at the 7th International Conference on Thinking, http://www.nas.gov.sg/archivesonline/speeches/record-details/77677402-115d-11e3-83d5-0050568939ad. Last accessed in June 2018.

[11] Greeno, J. G., Collins, A. M., \& Resnick, L. B. (1996). Cognition and learning. In Handbook of Educational Psychology, D.C. Berliner and R.C. Calfee (Eds). New York: Macmillan.

[12] Harvard Graduate School of Education website https://learnweb.harvard.edu/alps/thinking/docs/Dispositions.htm. Last accessed June 2018.

[13] Johnson, D.W., Johnson, R., Stanne, M.B., \& Garibaldi, A. (1990). Impact of group processing on achievement in cooperative groups, Journal of Social Psychology, 130(4), 507-516.

[14] Jonassen, D. H. (1994). Thinking Technology: Toward a constructivist design model. Educational Technology, 34(3), 34-37.

[15] Marsh, D., \& Frigols, M. J. (2013). Content and language integrated learning. In C. Chapelle (Ed.) Blackwell Encyclopedia of Applied Linguistics (pp. 911-20). Blackwell Publishing.

[16] Mostrom, A. M., \& Blumberg, P. (2012). Does learning-centered teaching promote grade improvement? Innovative Higher Education, 37(5), 397-405.

[17] Nunan, D. (1988). The learner-centered curriculum. Cambridge: Cambridge University Press.

[18] Opfer, D and Pedder, D. (2011). Conceptualizing Teacher Professional Learning. Review of Educational Research, 81(3), 376407.

[19] Prawat, R., \& Floden, R.E. (1994). Philosophical perspectives on learning theory. Educational Psychologist, 29(1), 37-48.

[20] Reeves, T. (1992). 'Effective Dimensions of Interactive Learning Systems' Keynote address for Information Technology for Training and Education Conference (ITTE '92).

[21] Ritchhart, R., Church, M., \& Morrison, K. (2011). Making thinking visible: How to promote engagement, understanding, and independence for all learners. San Francsico: Jossey-Bass.

[22] Teine, D. (2000). Online discussions: A survey of Advantages and disadvantages compared to face-to-face discussions. Journal of Educational Multimedia and Hypermedia, 9(4), 371-384.

[23] Van Meter, P. \& Stevens, R.J. (2000). The role of theory in the study of peer collaboration. Journal of Experimental Education, $69,113-129$.

[24] Vrasidas, C., Zembylas, M. and Chamberlain, R. (2003b). The Design of Online Learning Communities: Critical Issues, paper presented at the Annual Conference of the International Council of Educational Media, Oslo.

[25] Writesite. University of Sydney http://writesite.elearn.usyd.edu.au/Last accessed April 2018.

[26] Zwiers, J. (2008). Building academic language: Essential practices for content classrooms. San Francisco, CA: Jossey-Bass.

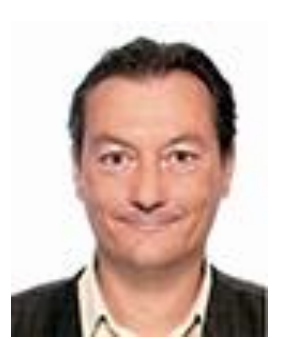

Mark is designer and teacher of two multi-disciplinary academic English courses entitled Sport and Competition (1st year) and Sport and Socialization (2nd year) at the National University of Singapore. These focus on developing critical thinking skills and spoken and written communication skills by analyzing how society and sport are interrelated. Over the last 20 years, Mark has practiced as an educator in France, the UK, Italy, the PRC, Hong Kong and Singapore. He has presented at conferences in Singapore and other ASEAN countries and has published in internationally-refereed journals in the fields of English language teaching and learning as well as sport studies. 